УДК 336.02

DOI $10.21661 / \mathrm{r}-530186$

\title{
В.В. Соломатова
}

\section{ИНФЛЯЦИОННОЕ ТАРГЕТИРОВАНИЕ:}

\section{ПРЕИМУЩЕСТВА И НЕДОСТАТКИ}

Аннотация: в научной статье рассматриваются преимущзества и недостатки инфляционного таргетирования в России с учетом мирового опьта. Проанализирована роль ключевой ставки как основного инструмента денежнокредитной политики. В работе затронута тема выгоды и недочеты перехода к инфляционному таргетированию в России.

Ключевые слова: инфляц̧ионное таргетирование, инфляц̧ия, денежнокредитная система, банковская деятельность.

\section{V.V. Solomatova}

\section{INFLATION TARGETING: ADVANTAGES AND DISADVANTAGES}

Abstract: in this article, inflation targeting in Russia is considered, taking into account international experience. The role of the key rate as the main instrument of monetary policy is analyzed. The study also deals with the benefits and shortcomings of the transition to inflation targeting in Russia.

Keywords: inflation targeting, inflation, monetary system, banking.

Важным элементом экономической политики государства является формирование новой денежно-кредитной системы и создание правовой основы для эффективного осуществления банковской деятельности в Российской Федерации. Банк России является органом банковского регулирования и банковского надзора, цель которых заключается в поддержании стабильного уровня банковской системы и защите экономических агентов.

Главным инструментом регулирования банковской деятельности является учетная ставка ЦБ (ставка рефинансирования) - размер процентов в годовом исчислении, подлежащий уплате Центральному банку России за кредиты, которые ЦБ предоставил кредитным организациям. Таким образом, ключевая ставка представляет собой ставку, устанавливаемую Центральным банком для оказа- 
ния прямого или косвенного воздействия на уровень процентных ставок, складывающихся в экономике страны, которое происходит через кредитование Банком России коммерческих банков. То есть, с её помощью происходит воздействие на экономику с целью достижения планируемого уровня инфляции.

Регулирование ключевой ставки является основным инструментом денежно - кредитной политики. Это было официально заявлено начиная с 13 сентября 2013 г.

Именно в этот день было принято решение по введению комплекса мер по модернизации инструментов системы денежно-кредитной политики в рамках перехода к режиму таргетирования инфляции. Что касается политики центральных банков, то остаются вопросы на сегодняшний день, которые остались без ответов, однако все же определенные направления денежно-кредитной политики были сформированы, которые и легли в её основу. Это и способствовало возникновению такого режима, как таргетирование инфляции.

Инфляционное таргетирование - режим денежно-кредитной политики, при котором главной задачей центрального банка становится поддержание стабильно низких цен в экономике. В реальной жизни это означает, что когда возникает риск высокой инфляции, то Центральные банки начинают повышать процентную ставку. Однако снижение инфляции служит сигналом к смягчению денежно-кредитной политики, то есть снижению ставок.

Сторонники инфляционного таргетирования считают, что главным преимуществом данного режима денежно-кредитной политики является поддержание цен на одном стабильном уровне. Ценовая стабильность имеет определенные преимущества, благодаря которым у экономических агентов появляется уверенность в стабильности экономики, планирование составляется на более продолжительное время, объемы кредитования растут, в экономике появляется больше длинных денег, у бизнеса и населения возникает больше стимулов к инвестициям, экономика начинает расти. Ценовая стабильность устанавливается в долгосрочной перспективе по мере роста доверия к национальной валюте, денежным властям и той политике, которую они проводят. Иными словами, 
выбирается целевое значение инфляции и за счет этого согласовываются потребительские цены.

При инфляционном таргетировании для положительной макроэкономической динамики уделяется повышенное внимание установлению низких инфляционных ожиданий. Основным принципом таргетирования инфляции в этом случае является поддержание открытой политики, при которой исключаются иные обязательства Центрального банка, которые не соотносятся с целью установления низкого уровня инфляции.

С другой стороны, хоть такой режим денежно-кредитной политики и обещает положительную ситуацию, он вряд ли перекроет те потери, которые несет экономика и реальный сектор в настоящем из-за роста процентных ставок и низкой доступности кредита. На примере России это можно отследить, если в случае ужесточения санкций, усиления напряженности в мировом сообществе, нового кризиса на развивающихся рынках, большой амплитуды колебаний нефтяных цен и рубля Банк России может отложить переход к нейтральной монетарной политике. В таком случае, хоть экономисты и утверждают, что положительный эффект от таргетирования инфляции наступает через 3-5 лет, этот срок может значительно увеличиться.

Что касается среднесрочной перспективы, то Центральный банк имеет возможность оказывать влияние на макроэкономическую динамику, но без изменения трендов реальных показателей. Поддерживая рост цен на активы и снижая ключевую ставку, Центральный банк регулирует процентные ставки и объем денежного предложения. В противоположном направлении это так же реально, за счет увеличения ключевой ставки и уменышения объема денег на рынке, при этом такое регулирование денежного обращения позволяет Центральному банку эффективно управлять экономическими циклами и смягчать их.

Мировые тенденции на сегодняшний день показывают, что большинство стран мира массово перешли на таргетирование инфляции, при том что ранее активно практиковали монетарное таргетирование. Этот переход произошел прежде всего из-за неэффективности обеспечения ценовой стабильности. При 
монетарном таргетировании было невозможно установить устойчивый спрос на деньги и за счет этого можно было наблюдать скачки процентных ставок при фиксированном предложении денег на рынке [1, с. 15-18].

При инфляционном таргетировании все происходит от обратного: Центральный банк, наоборот, устанавливает ключевую ставку, по которой банковский сектор имеет возможность приобрести ресурсы в том объеме, в котором он нуждается. То есть от ключевой ставки зависит, по какой цене в свою очередь, коммерческие банки будут предлагать денежные ресурсы реальному сектору - бизнесу, предприятиям, физическим лицам.

Для обеспечения равновесия должен быть обеспечен такой уровень ключевой ставки, при котором разрыв между инфляцией и выпуском будет минимальным. Нормальной реакцией для такого равновесия будет считаться снижение процентной ставки вслед за уменьшением инфляции, и наоборот.

Результат от проводимой политики ценовой стабильности проявляется только спустя продолжительное время, так как реальный сектор только после снижения неопределенности пересматривает свои инфляционные ожидания. Однако отрицательные последствия могут наступать моментально после ужесточения денежной политики и увеличения процентной ставки. Однако как только экономические агенты приспосабливаются к изменениям, сдерживающее влияние политики высоких цен исчезает. Стоит отметить, что данные меры принимаются властями из-за краха режима фиксированного курса, что сопровождается снижением роста ВВП, безработицей, сокращением инвестиций и уменьшением объемов кредитования [5, с. 62].

Российский опыт показывает, что адаптация к новой денежно-кредитной политике произошла лишь спустя несколько лет после начала её внедрения, так как только к 2018 году разрыв между уровнем инфляции и ключевой ставкой приблизился к нейтральному значению. Тем не менее ещё рано говорить о позитивных эффектах, так как на данный момент были достигнуты только уменьшение ставок по долгосрочным займам и увеличение сроков кредитования за счет некоторой уверенности реального сектора в макроэкономической 
стабильности. Таким образом, хоть сторонники инфляционного таргетирования и заявляют, что сроки проявления положительных тенденций проявляются в течении 3-5 лет, однако реальная ситуация показывает, что эти сроки будут увеличены.

Таргетирование инфляции как режим денежно-кредитной политики в мировой истории существует довольно давно, за счет чего и был накоплен опыт его применения. На основании успешного применения в экономике данного режима, все больше стран переходит от монетарной политики к режиму таргетирования инфляции. Успех данного режима был обеспечен гибкостью Центрального банка к изменениям в экономике, при условии низкого уровня инфляции. Данный режим позволяет сформировать доверие к национальной валюте.

\section{Список литературы}

1. Выгоды и издержки инфляционного таргетирования в России / П.В. Трунин, А.В. Божечкова, Е.Л. Горюнов [и др.].- М.: Издательский дом «Дело» РАНХиГС, 2019. - 60 с.

2. Горюнов Е. Банк России на перепутье: нужно ли смягчать денежнокредитную политику / Е. Горюнов, П. Трунин // Вопросы экономики. - 2013. №6. - C. 29-44.

3. Картаев Ф. Оценка влияния монетарной политики на экономический рост для различных групп стран // Финансы: теория и практика. - 2018. T. 22. - №1. - C. 50-63.

4. Основные направления денежно-кредитной политики на 2019 г. и период 2020 и 2021 г. / Банк России. - 2018.

5. Трунин П. О чем говорит мировой опыт инфляционного таргетирования / П. Трунин, А. Божечкова, А. Киюцевская // Деньги и кредит. - 2015. №4. - C. 61-67. 


\section{References}

1. Trunin, P.V., Bozhechkova, A.V., \& Goriunov, E.L. (2019). Vygody i izderzhki infliatsionnogo targetirovaniia v Rossii., 60. M.: Izdatel'skii dom "Delo" RANKhiGS.

2. Goriunov, E., \& Trunin, P. (2013). Bank Rossii na pereput'e: nuzhno li smiagchat' denezhno-kreditnuiu politiku. Voprosy ekonomiki, 6, 29-44.

3. Kartaev, F. (2018). Otsenka vliianiia monetarnoi politiki na ekonomicheskii rost dlia razlichnykh grupp stran. Finansy, T. 22, 1, 50-63.

4. Osnovnye napravleniia denezhno-kreditnoi politiki na 2019 g. i period 2020 i $2021 \mathrm{~g}$.

5. Trunin, P., Bozhechkova, A., \& Kiiutsevskaia, A. (2015). O chem govorit mirovoi opyt infliatsionnogo targetirovaniia. Den'gi i kredit, 4, 61-67.

Соломатова Виктория Викторовна - магистрант, Сибирский институт управления (филиал) ФГБОУ ВО «Российская академия народного хозяйства и государственной службы при президенте Российской Федерации, Новосибирск, Россия.

Solomatova Victoria Viktorovna - master's degree student, Siberian Institute of Management (branch) of the Russian Presidential Academy of National Economy and Public Administration, Novosibirsk, Russia. 